\title{
IMAGINARIO HUILLICHE CHILOTE. REFLEXIONES DESDE LA ACCIÓN Y REACCIÓN DE LA FEDERACIÓN HUILLICHE DE CHILOÉ
}

\author{
THE IMAGINARY HUILLICHE OF CHILOÉ. REFLECTIONS \\ FROM THE ACTION AND REACTION OF THE HUILLICHE \\ COMMUNITY FEDERATION OF CHILOÉ ISLAND
}

\author{
Michel Duquesnoy ${ }^{1}$
}

\begin{abstract}
Chiloé y su archipiélago constituyen un mundo en sí en el que el sentimiento de pertenencia es fuerte. A ello se junta la identidad de los mapuche huilliche que, en este espacio, viven e intentan mantener el orgullo de un pueblo originario particularmente golpeado por los meandros de su historia. De ahí la aparición de varios cuestionamientos a la afiliación identitaria que reivindican -o no-los actores. Cuestionamientos y actitudes que pueden llegar a la negación de pertenencia al pueblo mapuche huilliche de Chiloé. La experiencia y las informaciones recopiladas para este ensayo acerca de la Federación de Comunidades Huilliches de la Isla de Chiloé sirve al autor para reflexionar en torno a la construcción de los referentes identitarios en contextos vividos por los grupos subalternos o, si se quiere, desde la perspectiva de varios informantes y con sus propias palabras, por un pueblo vencido.

Palabras claves: Chiloé, huilliche, identidad, grupo subalterno, Federación de Comunidades Huilliches de la Isla de Chiloé.

Chiloe and its islands are a world apart, and there is a strong sense of belonging. Moreover, it is here that the Mapuche Huilliche identify themselves, live and struggle to maintain their pride as native peoples, while being particularly down trodden by the trajectory of their history. Hence the appearance of several challenges to the identity the actors claim affiliation to - or not to. Questions and attitudes can negate their belonging to the Mapuche Huilliche of Chiloé. The experience and the information collected for this essay about Huilliche Community Federation of Chiloe Island helps the author reflect on the construction of identity in contexts experienced by subaltern groups or in the words of multiple informants, from the perspective of a vanquished people.
\end{abstract}

Key words: Chiloé, Huilliche, identity, Subaltern Group, Huilliche Community Federation of Chiloé Island.

No es sorprendente recordar que en la gran mayoría de los aspectos constitutivos del fenómeno social, la Isla de Chiloé y su archipiélago constituyen un mundo en sí, presentando todavía diferencias profundas con el Chile continental. Tal constatación se extiende evidentemente a la presencia humana y en el caso que nos interesará, a los mapuche huilliche insulares. Sin embargo, no es nuestro propósito acentuar la otredad chilota, y menos huilliche, dado los peligros y engaños que una "alterización" de un "ellos" diferentes podría dar la impresión de una radical diferenciación, la que resultaría del todo impropia en definitiva para entender los vaivenes complejos entre lo local y lo global; lo regional y lo nacional; lo social y lo cultural, etc. Deseamos emitir la precaución por nada baladí que, en este espacio, en ningún momento consideramos al mundo huilliche chilote (y continental) como un "bloque" unificado o "reificado" (por la magia de los artefactos antropológicos). No obstante, debe ser claro y convenido que sí existe un conjunto cultural diferente que se declara discreta o firmemente "mapuche". Pueblo compuesto de sujetos que el autor solo desea objetivar con moderación. Es más, no deseamos definir, "esencializar" y/o objetivar la mirada y discurso de los actores sobre ellos mismos, menos la del antropólogo pero sí reflexionar sobre y desde una de las perspectivas más complejas (y

\footnotetext{
1 Observatorio Regional de Paz y Seguridad (ORPAS). Universidad Bernardo O’Higgins. Av. Viel 1497. Santiago, Chile. butahuapichilhue@hotmail.com
} 
aleatorias) que son: nos referimos a la experiencia cotidiana de los actores e informantes, arriesgándonos a interpretar más que a relatar precisamente la narrativa de los que han declarado adscribirse al pueblo huilliche de Chiloé.Nosotros postularemos una gran continuidad entre el huilliche insular y sus hermanos continentales, y eso sí pese a claros particularismos irrebatibles, muestras profundas de un increíble dinamismo cultural entre los miembros del pueblo mapuche. En este espacio, no revisaremos tales singularidades.

Será otro problema cuestionar la existencia y persistencia de una identidad huilliche chilota, tema latente y subyacente de este trabajo. Al fin y al cabo, si es permitido aseverar las singularidades indígenas por parte de los huilliche chilotes en un pasado todavía reciente, será bastante sugestivo cuestionar los fenómenos contemporáneos que los trastornan e imponen reconfiguraciones eventuales por parte de los actores que se supondría interesados en la pervivencia de lo que ha sido su originalidad cultural. Además, nos parece interesante contemplar un dato determinante en este debate; el que Chiloé y sus habitantes originarios conocieron una tutela y una presencia permanente de españoles desde 1641. "La primera pérdida del territorio huilliche fue Chiloé". (Programa de Derechos Indígenas, 2003:300, cursivas en el original).

El autor de este trabajo revisará brevemente los puntos señalados anteriormente bajo el ángulo de la Federación de Comunidades Huilliches de la Isla de Chiloé, organización indígena paradigmática, a nuestro parecer, de los entendibles esfuerzos demostrados por los propios mapuche, para recrear, tanto como se pueda, el orgullo de una nación vencida.

Vale precisar que las reflexiones que propone el autor se fundamentan en largas conversaciones con múltiples actores perteneciendo autodeclaradamente al pueblo huilliche de Chiloé. Pocas de las mismas fueron dirigidas durante el árido ejercicio de la entrevista. Es decir, en diálogos profundos en los que el antropólogo llega a disfrutar la convivencia de sus huéspedes durante las frías tardes chilotas. De ahí su elección deliberada de exponerse a los trances del ensayo más que a una discusión con autores y teorías antropológicas. Esta elección es, en definitiva, un riesgo asumido conscientemente puesto que el tema que se desarrollará en seguida probablemente refleja aspectos altamente subjetivos por parte de los informantes a los que, no ingenuamente, intentará no ceder el que escribe.
Probablemente la promulgación y aplicación de la hoy obsoleta Ley Indígena 19.253 de 1993, han favorecido el tipo de organizaciones indígenas como la que consideramos en este espacio, las que sirvieron de interfaz legal para los trámites relacionados, entre otras cosas, con la restitución de las tierras usurpadas por el Estado chileno. Igualmente se presentará un esbozo de reflexión en torno a los procesos de (de) construcción de los imaginarios huilliche chilote en un tenso contexto de ordenaciones identitarias a nivel individual y colectivo, como espejo de una profundad mutación en la percepción del afirmar ser o del alejar ser mapuche.

La idea principal de este trabajo no es y no será postular la existencia de una identidad huilliche chilota como si la misma fuese una hipóstasis perteneciendo solo al cielo de un esencialismo poco creíble. Más bien este ensayo propone una lectura en torno a la percepción particular de su especificidad que hacen de sí mismos ciertos actores perteneciendo a una nación originaria cuya historia de despojos y trastornos por parte de una nación decididamente unitaria no ha de ser descrita en este espacio. Frente al giro inesperado que dieron varios informantes al hablar de su "condición huilliche chilote" actualmente, el autor de este trabajo tuvo que evaluar la altura de los trastornos que los mismos afirman vivir con grados muy variables de dificultades. En definitiva, y a priori, son los actores que viven una situación que le es propia. Situación cuyos materiales recopila el estudioso para así analizar e intentar, en la medida de sus posibilidades, repercutirles con interpretaciones que se desea no tan lejanas de la realidad experimentada por sus informantes. En fin, el desafío era evaluar la "dureza" o "blandura" (Rachik 2006) del molde cultural al que verosímilmente una porción de la población autodeclaradamente huilliche se refiere o se aleja para "construirse" cultural, simbólica, sociológica y políticamente. El texto que sigue, pese a sus innumerables lagunas, esboza posibles respuestas que, a su vez, deberían ser ampliadas en una monografía mucho más detallada.

\section{Malestares Culturales y Tensiones Antropológicas}

Es aquí el lugar, para revisar nuestro tema, para proporcionar al lector unas precisiones claves -estimamos que es la mera médula de este ensayo- para entender lo que pretendemos analizar y esbozar 
tanto a nivel teórico como a nivel del conocimiento en torno a un contexto indígena complejo y, valga lo que valga la redundancia, nunca estático, nunca idéntico a las proyecciones y especulaciones de los cientistas sociales, en particular etnólogos. En efecto, la cultura occidental eminentemente monológica, en la que estamos inmersos y socializados, nos alienta a construir una visión monolítica de los grupos perteneciendo a mundos diversos, como es el caso de los universos indígenas o de las minorías sociales. Es decir, una percepción de "los otros" desde un "nosotros", como si los primeros sólo lograsen, desde su supuesta cacofonía, representar algún tipo de aberración o incongruencia existencial. El discurso de los antropólogos y otros estudiosos que dedican sus esfuerzos a entender al mundo mapuche no hace más que establecer una singular idiosincrasia definitoria de las personas perteneciendo a este pueblo, como si se pudiese identificarles como un grupo homogéneo. Hecho común a las apreciaciones de los medios masivos y del poder político que, reconozcámoslo, no cesa de cuestionar la inconveniencia de esta postura entre los antropólogos. En suma, ¿es posible -y deseable- presentar al pueblo mapuche como si fuera uno, monolítico, hilvanado y acorde a un solo eje de pensamiento aun supuestamente ancestral que le dispusiera a fomentar y defender como un solo bloque, un programa de acción para su pervivencia y configurar un solo perfil identario? La respuesta es obvia: ¡no!

Con todas las precauciones necesarias, es posible utilizar la noción de "campo social" que exploró Pierre Bourdieu en varios de sus trabajos (1980a, 1980b, 1984, 1987, 1994). De manera lacónica, basta con recordar que el mundo social puede considerarse como una cancha en la que interactúan los actores sociales, pero de manera desigual, ya que cada uno ocupa en él una posición distinta, combinando elementos similares y hasta contradictorios, generando "un" campo cuyas normas y funcionamientos pueden variar de manera apreciable aunque cada uno de los agentes (o grupos en presencia) se ve preocupado en llevar adelante sus intereses y aspiraciones, respondiendo a contextos culturales e históricos propios, es decir, subjetivos. Pues las estrategias se adaptan y no es de extrañar que sean frecuentemente las aspiraciones estructurales -motores mucho más potentes que las situaciones estructurales de origen-las que fortalecen las estrategias susceptibles de posicionar exitosamente las aspiraciones individuales y/o colectivas.

Invariablemente al tratar de los huilliche presentes en las islas del archipiélago de Chiloé, el investigador se percata de la existencia de un caleidoscopio cultural y organizativo que no permite destrabarse tan fácilmente. Nosotros partimos de una realidad (porque sí lo es) irrebatible: "Cuando la cultura mayoritaria universaliza sus características como las 'formas adecuadas de ser' [eso] provoca una especie de rechazo de sí mismos entre los miembros de los grupos minoritarios, que tratan de internalizar los rasgos distintivos de esa cultura mayoritaria". (Díez, 2004:54. Comillas en el original). Igualmente defendemos la idea de la libertad de elección cultural a la que se ve confrontado el mapuche a la hora de "sentirse y declararse" mapuche o no. Después de todo, la imposibilidad de dar criterios definitivos de la "indianidad" (o, en nuestro caso, de la "mapucheidad") apunta hacia las incongruencias identitarias así como a las inconsistencias aparentes de ciertos movimientos mapuche.

Sin embargo, partimos también con la evidencia de que existen actores indígenas que afirman su pertenencia étnica con orgullo y con la esperanza entendible de recobrar su dignidad mapuche. Entiéndase, su autonomía -cualquiera sea el grado en que entienden ubicarla y vivirla-. Por tal motivo, Chiloé no ofrece la imagen de un mundo estático e inmutable para y entre sus habitantes originarios, más bien es un crisol dinámico con sus logros y fracasos, aunque seguramente prevalezcan los cuestionamientos propios a un pueblo indígena fragmentado, derrotado y humillado que vive, a su manera y a su ritmo, con sus (des)esperanzas y utopías. Postulamos que son tres generaciones sucesivas que conviven a la fecha, en el mismo espacio simbólico, geográfico, social y cultural, cada una con su apreciación distintiva del entorno sociohistórico en el que, las tres, están (o estuvieron) inmersas: la generación de la predictadura, la dictadura y la postdictadura. Si nuestro postulado tiene alguna suerte de convencer, es legítimo entablar por lo menos tres percepciones diferentes, aunque complementarias, de las mutuas relaciones del Estado chileno con los mapuche en general y los huilliche chilotes en particular. En efecto, cada momento histórico puso en marcha políticas "indigenistas" diferenciadas cuyos impactos han sido vividos e incorporados de modo distintivo por estas tres generaciones -en el sentido de las disposiciones internalizadas y grabadas en el cuerpo, como lo postuló Bourdieu al discurrir 
en torno al habitus-. Es decir, existiría una suerte de preentendimiento del entorno forjado a partir de la socialización (transmisión), la cultura (herencia), y la construcción/reacción del entendimiento en la que cada actor social participa recreando sus pautas culturales y escribiendo las páginas de la historia de su grupo, comuna, barrio, familia, etc. En fin, algo que reflejaría en suma "nuestra necesidad objetiva de protección y ayuda mutua en el grupo solidario [y] nuestra necesidad de activa organización y afirmación subjetivas" (Martínez, 2005:14. Énfasis nuestro) para la construcción paradójica de nuestras singularidades, imaginarios y referentes indispensables, postulamos, eso sí en perpetua modelación.

En definitiva, lo que deseamos resaltar es el hecho de que los integrantes de cualquier formación sociocultural que fuere, sometido o no, subyugado o no, aplastado, derrotado o vencido o no; hegemónico, dominante, vencedor o no, todos los integrantes participan en un doble movimiento de construcción activa y pasiva (eso es, construyen y son construidos) por la cultura y los complejos mecanismos socio/económico/geográfico/ideológico/ simbólico que sí generan, modifican, trastornan los moldes culturales y las expresiones, esperanzas, alcances, etc., de dicho grupo cultural.

En suma, la construcción y absorción de las pautas conductuales sobre las cuales se edifica la "singularidad" de un grupo cultural reposan sobre un substrato subjetivo innegable, difícilmente conmensurable pero sí favorable a la comprensión de "sí mismo, [de] los otros y [del] mundo" (Walsh, Mignolo y García 2006:105). Actitudes que no dejan de tener implicaciones, sea dicho de paso, sobre las habilidades políticas de los actores.

Vemos que los mecanismos dialécticos existentes entre las condiciones vividas y las experiencias compartidas generan respuestas indefinidas que oscilan entre la perduración en el tiempo y la generación de actitudes puntuales, pero variables en la contingencia cuando se trata de responder a requerimientos cotidianos precisos. En resumen, es menester considerar -aventura complicada para el observador externo- el sutil punto de vista con el que se conciben los grupos humanos a sí mismos y cómo se visualizan en el presente para posibilitar una proyección en el futuro.

En el caso mapuche en particular, creemos posible de aseverar que, frente a tal contexto, nunca o escasas veces, se puede presentar y defender un eje inmutable, tanto en las decisiones y posturas individuales como colectivas, sean culturales o políticas. Al fin y al cabo, la incertidumbre domina dentro de los sistemas culturales abiertos a las fluctuaciones debidas a un entorno complejo principalmente dominado por una estructura hegemónica restrictiva, una cruda asimetría relacional y una deplorable persistencia de violencias simbólicas. Con Sauriol, refiriéndose a Butler, pensamos que "la identidad ${ }^{1}$ no sea algo determinado sino un modo de ser que se crea y se recrea según el momento y las circunstancias, según el poder y la posición ocupada por el sujeto" (Sauriol 2005:5, énfasis mío). Todo elemento evidentemente presente en la dinámica cultural experimentada por los huilliche de Chiloé, los que, a nuestro parecer, podrían ser afectados por una falta de iniciativa relacional por parte del Estado y de nexos vinculantes con sus hermanos continentales de la Región de Los Lagos. Situación que imposibilita la creación de espacios dialógicos propios a su afirmación y autoestima, ya que en el propio grupo se elabora en parte no despreciable el amor propio. En suma, una situación repetida de deterioros será favorable a la fragmentación que, a continuación, revisaremos.

\section{Los Huilliche del Buta HuapiChilhué. Objetividades y subjetividades}

"La isla posee una población de 154.766 habitantes, el 15\% de ellos es población indígena" (Cuyul 2006:1). No obstante, no existen datos censales exhaustivos en torno a indígena para Chiloé. En una conversación sostenida en mayo de 2011, el propio Cuyul, líder de la Federación de Comunidades Huilliches, precisa que los mapuche contabilizan ciertamente un 60\% (si no más) de la población insular total. Pero la vergüenza que siente la mayoría al declarar alguna descendencia indígena disfraza el número real de la población originaria. Se detecta su origen huilliche por el apellido, sostiene. Fuera de ello, las concentraciones huilliche en Chiloé se encuentran principalmente en cuatro lugares: a lo largo de un eje que va grosso modo de Chonchi a Cucao (cortando la isla de este a oeste a la mitad geográfica de Chiloé); en el sureste, agrupando principalmente las comunidades de Compu, Yaldad, Yungay y Chadmo; en las islas del archipiélago; y aparecidas más recientemente, las "nuevas" comunidades formadas en el noreste en el sector de Tenaún y Quicaví. Respecto a la repartición política de lo que llamaríamos la "jurisdicción 
huilliche en Chiloé", el hoy controvertido sistema de cacicados $^{2}$ reúne principalmente las tradicionalistas comunidades del sur y la mayoría del oeste (sector de Cucao). Las "nuevas" parecen más autónomas y en cuanto a las comunidades del eje mediano este-oeste, la mayoría se ve afiliada de cerca o de lejos en la actualidad al radio de influencia de la Federación de Comunidades Huilliches.

En regla general, se puede afirmar que la condición socioeconómica de los indígenas de Chiloé es frecuentemente similar a la del conjunto poblacional insular cuyos índices de marginación y rezagos sociales son altos ${ }^{3}$. Vale hacer hincapié en que los actores entrevistados consideran habitualmente que ocupan un rango de rezago social inferior a la marginación general. Este hecho es declaradamente atribuido a la discriminación usual del entorno en su contra ${ }^{4}$.

A nivel de la organización sociopolítica interna, varias comunidades huilliche en Chiloé siguen respetando la figura del longko. El longko es una autoridad tradicional, un superior que tiene alguna forma de mando. Sin embargo, sus funciones son cada vez más simbólicas en nuestros días, pues se limitan a las de una figura de referencia más o menos considerada entre su gente, sobre todo entre las generaciones adultas. Su rol simbólico permanece importante en la indicada zona tradicionalista, ya que son "la autoridad máxima indígena dentro del fundo" (De la Calle 1986:47). Señalemos que su rol político es inexistente o sumamente limitado. En principio, no participan en las pugnas políticas partidistas aunque sí pueden tener preferencias políticas, que no pueden teóricamente imponer o difundir con pretexto del prestigio e influencia de su cargo. No parecen tener gran peso frente a las autoridades chilenas, aunque implícitamente se reconozca su rol interno en la rutina de las comunidades. Un longko entrevistado en el sector de Cucao sostiene que no dispone de ningún poder sobre su gente y son varios los casos de falta de respeto hacia la persona y el cargo de sus colegas por parte de la clase política. Además, no son consultados en los cenáculos de las tomas de decisión al momento de aplicar programas oficiales o disposiciones. En breve, lamenta los cambios profundos que trastornan a la población indígena generando entre los jóvenes el desprecio para sus orígenes y una grave pérdida de autoestima que va traduciéndose por el incremento del alcoholismo, entre otros disturbios graves.
Al nivel cultural, la situación es preocupante ya que casi todas las costumbres mapuche huilliche han desaparecido. El ejemplo paradigmático de ello, en palabras de los interesados, es la pérdida casi total del velichesugun que, en nuestros tiempos, constituye una realidad alarmante para muchos actores. En muy contadas escuelas primarias se enseña a veces sus rudimentos con un éxito limitado. En regla general, la asimilación a la cultura chilota es flagrante. Pese a iniciativas para recrear ciertas ceremonias rituales como el WeTripantu (solsticio de invierno), se asiste a una pérdida casi completa del aparato simbólico huilliche en el Buta Huapi. Peor aún, muchos informantes, reportan la falta de consideración por los propios huilliche hacia sus costumbres. "No les interesa", claman como un solo coro. Detrás de estas afirmaciones, ciertamente radicales, se perfila un problema interno mucho más profundo -en efecto, las manifestaciones señaladas son directamente observables-: el desconocimiento de sí mismo en cuanto a pueblo; el desmoronamiento orgánico de la cohesión comunitaria y el inevitable individualismo que mortifica las iniciativas a favor de la unión. Dicho de otra forma, son los vínculos identitarios "tradicionales" que se encuentran profundamente afligidos aunque puedan recrearse otros y nuevos como base imprescindible de la vida social e individual. Muchos índices apuntan hacia los programas asistencialistas, a veces discrecionales, los que debilitan las voluntades y crean dependencias a nivel familiar y malentendidos desembocando sobre, en palabras textuales de varios huilliche, "incomprensiones, rencores y chismes" a nivel comunitario. No obstante, existen probablemente factores de desfragmentación sutilmente arraigados y cuyos orígenes se manifestaron en una historia de mediana duración, hoy atrapados en las mallas de la descomposición identitaria. Solo intuimos esta posibilidad sin haber podido, a la fecha, profundizar esta hipótesis. Es más, es probable que para muchos huilliche de Chiloé, el sentirse aún inconscientemente en la difícil postura de lo que, en definitiva, cueste lo que cueste afirmarlo, es la situación de un pueblo si no derrocado, por lo menos vencido y humillado, genera posiblemente una condición sumamente subjetiva de insignificancia, desprecio cultural y social que también podría manifestarse por un fatal quebranto de la autoestima colectiva, rechazando probablemente a nivel inconsciente la herencia difícilmente tolerable de los traumas históricos bien presentes en la memoria colectiva. 
Es decir, la autorreferencia a "pueblo" se ve negada hasta desvanecerse. Dicho de otro modo, se escogería otro marco identitario en lugar de asumir el heredado.Vistas desde este ángulo peculiar, las dolencias no directamente observables por el investigador, sino confesadas por los actores directamente inmersos en su propia cotidianidad, tienen como nombre "malentendidos", "difamación", "envidia", "resentimiento", "individualismo exacerbado", "chismes", todos estos destructores de sus vínculos y afinidades comunitarias. Evidentemente los conflictos son necesarios para mantener una buena salud social, es una lección clásica de las ciencias sociales y humanas. Sin embargo, no se trata en lo que intentamos de subrayar de tensiones abiertas, sino de plagas de tipo psicosocial capaces de minar el tejido social que hila el entramado identitario de los grupos culturales. Sostenemos que las plagas a las que se unen, las conocidas consecuencias de los llamados etnocidios y egocidios, llegan a derrumbar hasta los vínculos de solidaridad. En este caso, la puerta está abierta a un acelerado proceso de descomposición cultural. Hecho que, en nuestra opinión, está ocurriendo en la actualidad entre la gran mayoría de los huilliche de Chiloé. De ahí a afirmar que el proceso registrado es irreversible, el autor de este ensayo no se atreve a sostenerlo.

Llegados a este punto de la exposición, parece útil aclarar nuestro enfoque acerca de los procesos conscientes e inconscientes, ya que en una oportunidad mencionamos al habitus de Bourdieu. Por no ser el lugar adecuado, no podemos entrar en discusiones profundas con el concepto bourdianano, pero sí enfatizar la afirmación explícita expresada claramente por una informante entrevistada en Piopio. Insiste la informante que son "abiertos nuestros sufrimientos y las humillaciones que sufrieron nuestros abuelos, o hasta hoy cuando nos atienden en la clínica, por ejemplo, porque somos mapuches" y "los jóvenes no quieren seguir viviendo asî" (agosto 2011). En nuestra opinión, los actores expresan con sus palabras y otras actitudes la incorporación inconsciente de los despojos de los que fueron víctimas. Y son sus esquemas de percepción, pensamiento y acción que en la mayoría de las veces de manera consciente se da libre curso, en sus estrategias de convivencia y sobrevivencia con los "ellos no son nosotros" (los llamados winkas). Pensamos que está fundada la posibilidad de la manifestación de un habitus de pueblo subyugado, o, si se prefiere, aplastado. En tal condición, es inútil insistir mucho sobre el movimiento dialéctico de acción/reacción que interactúa entre el individuo y el grupo, o viceversa ${ }^{5}$. O por decirlo con las palabras de Martín Criado:

Por último, la incorporación inconsciente del habitus no supone sólo la apropiación práctica de los esquemas que sirven para producir las prácticas adecuadas a la situación: supone también el hecho de que se incorpore el "interés" en jugar el juego. $\mathrm{Si}$ los agentes sociales juegan los diversos juegos de acumulación de capital -económico, simbólico, científico, etc.- no es porque estén determinados por un "interés" inscrito en su naturaleza, ni porque hayan decidido de manera reflexiva y racional interesarse, sino porque han incorporado este interés mediante la inmersión en un universo de prácticas que define lo que está en juego y lo que vale la pena. En otras palabras, han incorporado en su habitus -entendamos más allá de su reflexión y conciencia- unos esquemas apreciativos y evaluativos particulares (Martín Criado 2009 , cursivas en el original).

\section{Organizarse como Huilliche Chilote}

A pesar del poco halagador retrato que acabamos de esbozar, sí existen ciertas -aunque pocas- organizaciones legales por parte de los huilliche, todas presentando un nivel común de demandas específicas. Sin embargo, la dificultad aparece en el hecho de que estas organizaciones son disímiles en cuanto al tipo de "control comunitario" al que suscriben, sea el cacicado, sea la Federación o sean las otras existentes a la fecha. Considerando el problema desde este punto de vista, son todas las disensiones y rivalidades apenas disfrazadas entre estas suertes de poderíos que aparecen y que, a su vez, poco favorecen la cohesión entre todos los huilliche de Chiloé, ya que existen rivalidades abiertas entre estos "señoríos" que cubren, lo quieran o no, un área de influencia determinada.

Revisemos sin extendernos sobre el porqué se organizaron los indígenas, ya que es legítima y obvia su esperanza de mejorar, en gran parte, sus condiciones socioeconómicas y finalmente culturales. En pocas palabras, las organizaciones indígenas en Chiloé siguen, para sus objetivos, los patrones de sus similares continentales: valorizar sus derechos 
culturales, políticos y sociales; buscar y fomentar las oportunidades laborales; afrontar los problemas productivos (la mayoría son campesinos); tramitar la recuperación de sus tierras; fomentar la educación intercultural de sus niños; obtener fondos especiales de apoyo para las mujeres; canalizar y obtener los beneficios del Estado hacia los indígenas.

Los esfuerzos de estas organizaciones se concretizaron con éxito moderado en la primera mitad del decenio pasado. Si consideramos el lado de la cultura huilliche chilota, muchos actores toman la dimensión de las amenazas que pesan sobre su cultura con gran fatalismo, quizá con resignación. Y confiesan, como ya se comentó, su apatía, su falta de cohesión, la envidia y el individualismo. En escasos aspectos, los huilliche chilotes pudieron, en cierta medida, mantener un "tradicionalismo" genuino que les da un toque propio. Empero, muchos entre los propios huilliche insulares o entre los responsables culturales winkas que pudimos entrevistar, concuerdan con el diagnóstico del desgaste preocupante de sus referentes culturales. En los hechos, los vínculos con sus hermanos del continente parecen laxos. Son, en todos los casos, insuficientes para dar una cohesión general al conjunto huilliche. Extrañamente, nuestras entrevistas revelan que se sienten más afines con los mapuche de Temuco que con los de Osorno "porque son más activos", confiesan. Afirmación que no extrañará a nadie que estudia los movimientos y organizaciones mapuche.

La Federación que sirve de motivo a nuestras reflexiones nació en 1999. Agrupaba, en su momento de auge, unas 30 comunidades (hoy serían escasas decenas de personas que se reconocen en sus objetivos). Su enfoque inicial netamente social -tal vez más que cultural-favoreció la adhesión de muchos focos huilliche, notoriamente inconformes con las posturas del cacicado. A decir de su fundador hoy particularmente afectado por la desconsideración que dice sufrir por parte de los comuneros y por la falta de responsabilidad y realismo de los mismos, la inicial opción social que dio a la Federación fue ciertamente un "error" [dixit] ya que hubiese debido laborar, en primer lugar y con peculiar énfasis, para la recuperación de la autoestima cultural de los miembros entonces afiliados en esta agrupación. Básicamente él sostiene: "Mejorar en un primer momento las condiciones sociales para después, y una vez fortalecidos al nivel social, recuperarnos a nivel cultural como pueblo mapuche, $j$ eso fue un error! Hoy, después de 13 años de sacrificios, la gente se ha desunido más todavía. Y cada quien va por lo suyo" (conversación libre. Huillinco. 22.09.2011). Suponiendo que la desunión que demuestran deja lo cultural de lado.

Dice un manuscrito entregado al autor:

La Federación de Comunidades Huilliche
de Chiloé es una organización indígena
eminentemente rural; se funda el año 1999 ,
con la participación de 10 comunidades
indígenas, principalmente de las comunas
de Chonchi y Quellón [.] (...) además de
contar con 28 comunidades asociadas de
distintas comunas de Chiloé. Tiene un
Directorio constituido por 6 miembros,
quienes son elegidos por la asamblea cada
dos años, tiempo que dura su mandato (nota
personal, julio del 2011).

Sus cuatro líneas de acción principales son (respetando el orden del manuscrito citado): recuperación de Territorios ancestrales y manejo de recursos naturales (relacionada al bosque nativo, los derechos de agua dulce y borde costero); el fortalecimiento de la cultura mapuche huilliche; la promoción de la educación y salud entre las comunidades; el desarrollo productivo, económico y social. Como era de esperar, la Federación obtuvo éxitos en cada uno de estos rubros ${ }^{6}$ aunque los puntos por mejorar, pendientes o no satisfechos, son muy importantes debido a factores externos como la lentitud o pertinencia de la aplicación de las políticas públicas y a factores internos, como la preocupante falta de organización por parte de los comuneros (este punto apareció muy claramente en nuestra presencia durante una visita a un informante con el presidente). Este último enfatizó, con razón, la necesidad de unirse para enfrentar las dificultades administrativas en las cuales la CONAF somete a los comuneros.

La lectura del manuscrito mostraría, cuando se le considera con debida atención, un optimismo relativo. En efecto, la apreciación verbal por parte del responsable de los logros reales a nivel cultural matiza negativamente los alcances esperados. Todo indicaría, si nuestra interpretación es correcta, que la Federación se ha vuelto, con los años, una agencia de tipo ONG, gestora indispensable, más por su afán social ${ }^{7}$ que por sus pretensiones culturales, las que definitivamente concitan poco interés por parte de sus propios afiliados ${ }^{8}$. Lo que corre el riesgo de 
reducir su impacto a los objetivos de un club cultural sin una verdadera originalidad ni impacto en la comunidad. Sería, en este punto preciso, que la desesperanza de la Junta Directiva encontraría los motivos que la cuestionan en su existencia. Pues se manifiesta con crudeza y desaliento profundo sin poder ocultar un sentimiento de irritación y amargura frente a las perturbaciones intracomunitarias reveladas en otro apartado 9 .

Así las cosas, los que se apartaron del Consejo General de Caciques (cacicado) incriminan, brevemente dicho, el tradicionalismo del propio, su falta de transparencia, la ambigüedad de la gestión de sus asesores (antropólogos y juristas), su prepotencia, etc. En este trabajo, se entenderá la postura neutral del autor. En efecto, no toma posición ni opina respecto a los motivos de las discordias que dividen a las comunidades huilliche de Chiloé entre sí. Sólo le es permitido enfatizar las probables consecuencias nefastas que generan tales desacuerdos, como es la dificultad de construir un devenir para el pueblo huilliche de Chiloé. Dicho de otra manera, sí deplora los peligros reales que le debilitan y empobrecen en todos los aspectos.

La Federación de Comunidades Huilliche de la Isla de Chiloé, con sus altibajos, ha servido evidentemente de pretexto ejemplar para un examen en torno a la situación preocupante del presente social, político y cultural del pueblo huilliche en Chiloé. No obstante, es importante subrayar que los datos reportados y los análisis de nuestra parte, ni deben ser considerados como despectivos hacia la Federación, su dirigencia y sus miembros; menos como juicios o sentencias en torno a su evolución, logros y fracasos. En definitiva, es igualmente el momento para avanzar la idea de que los serios problemas que la sacuden se encuentran sin ningún lugar a dudas en todas las asociaciones mapuche. La Federación, hoy, resulta ser como un espejo de la vida normal dentro de un pueblo profundamente humillado y sacudido por entendibles tensiones contradictorias.

A continuación, se propone un esbozo de reflexión acerca de los trastornos de la identidad entre los mapuche huilliche.

\section{Esbozar una Reflexión}

El filósofo mexicano Luis Villoro (1998) escribió un pequeño ensayo al que acudiremos para nutrir nuestra reflexión. Es una manera de reconocer nuestra deuda hacia un estudioso cuyo trabajo sirve para alimentar, bien a su pesar, el debate que pretendemos suscitar.

En definitiva, ¿cuál es el problema profundo que fundamenta la descomposición cultural entre los huilliche de Chiloé?

Como primera propuesta, postulamos que los conceptos básicos sobre los cuales se construye y mantiene la identidad de cualquier cultura, si son profundamente humillados, afectados, y por ende, amenazados con la desaparición, estos conceptos deben ser reinventados para asegurar un resurgimiento relativamente logrado y fuentes de enriquecimiento para los miembros de esta cultura. Planteamientos esenciales como: ¿qué se puede llegar a ser?, ¿qué se quiere llegar a ser?, siendo huilliche, tanto a nivel individual como colectivo son, por así decirlo de manera brusca, inexistentes. Esta carencia de espejo identitario claramente diseñado nos parece preocupante porque entorpece la reconstrucción identitaria (tan clamada por los propios mapuche) y la (auto) consideración hacia sí mismos (como individuo a la par de su colectividad). Quedaría por discutir la existencia o su eventual inexistencia de algún deseo para reconstruir una identidad perdida o sencillamente para mejorar su posición como miembros de una comunidad. Entonces ¿cuál sería la identidad imaginada que se proponen alcanzar los huilliche de Chiloé?

Para iniciar la segunda pista de reflexión, consideramos digna de interés para este esbozo una afirmación-que aquí retiramos arbitrariamente de su contexto-. La debemos a Raúl Fornet-Betancourt (s/f:159). De la cita, es preciso avisar que aislamos unos elementos útiles. Escribe en "Lo intercultural: el problema de su definición": "Es decir, bien en personas que con sus prácticas culturales contribuyen a ensanchar el espacio intercultural, bien en un obstáculo para su crecimiento, si nos cerramos y nos empeñamos en trabajar la 'pureza' de nuestra identidad".

Veamos las dos alternativas propuestas por el filósofo. De un lado, afirmamos que sí existen entre los mapuche así como entre los winkas, personas que trabajan con el objetivo principal el engrandecer, como única vía posible, un espacio intercultural de convivencia. De otro lado, existen lamentablemente en ambos campos, actores que alzan una supuesta "pureza" de su respectiva identidad. Lo que, definitivamente, impide una mutua y provechosa construcción/reconstrucción de sí mismos en los 
espacios geográficos, sociales y culturales que la historia de los pueblos les ha reservado probablemente a su pesar. Pero acaso, ¿cuestionan el pasado con los ojos del pasado? O, ¿del presente? Siquiera, ¿cuestionan? o ¿imaginan? En este caso puntual, la existencia de un espejo identitario imaginado hasta sus peores consecuencias es compartida tanto entre los activistas mapuche más virulentos como entre los nacionalistas winkas, con la inevitable consecuencia que los vencidos internalizan siempre mal los dictados del vencedor hasta negarse su propia identidad o vanagloriarla hasta la sobredosis. Y el que piensa ocupar un rango inferior se hundirá siempre más en la percepción de su derrota cuando el que piensa ocupar el lugar del vencedor seguirá soberbio en sus decisiones. Ambas figuras, en definitiva, paralizan la apreciación identitaria propia, compartida y mutua.

Como tercera pista de reflexión, enfatizaremos una redundancia. En suma, las confrontaciones, conflictos y tensiones siempre están presentes en los colectivos, independientemente de su condición de oprimidos o dominantes. Por lo tanto, sólo existen grupos sociales y culturales heterogéneos y fracturados. No es deseable -sin insistir sobre la imposibilidad de facto de alcanzar tal objetivo- que sean un todo compacto en razón de la artificialidad y de los peligros intrínsecos que tal estado presentaría. La diversidad social y cultural se experimenta laboriosamente en la complejidad de lo que realmente existe: un equilibrio frágil entre la cohesión y la fragmentación, equilibrio que está visiblemente amenazado hoy en día por la desfragmentación colectiva de los huilliche de Chiloé, su excesivo individualismo y las plagas de la envidia y chismes sociales, rasgos eminentemente compartidos entre los humanos después de todo y en ningún momento determinante de la idiosincrasia huilliche pese a comentarios explícitos por parte de varios interlocutores indígenas que sí afirmaban tajantemente: "Somos envidiosos, somos chismosos. Así somos aunque me cueste reconocerlo"10. Esto provoca entre ellos mismos muy poca credibilidad y bastante baja autoestima. En segundo lugar, genera un sentimiento de rechazo entre los que se considerarán solamente como presas débiles e inconsistentes al momento de aplicarles decisiones a las que les dejaron arrinconadas. En breve, si hasta entre los propios huilliche la representación intersubjetiva es inexistente o, en sus niveles más bajos, el "sí mismo" colectivo se ve amenazado de rearticulación irrevocable, ¿en qué sentido y premisas dará esta rearticulación? Dice Villoro (1998:55) (como advertencia): "El problema de la identidad de los pueblos remite a su cultura". Y, en lo que en nuestro caso podría sonar como una moraleja, la confrontación y la exclusión no se dan solamente entre grupos diferentes en situación de asimetría de poder, sino que también se dan al interior de un mismo grupo. Donde las consecuencias a mediano plazo son tremendamente fatales, especialmente cuando este grupo está en la condición en que se encuentra el pueblo huilliche chilote actualmente.

\section{(De)Construir una Identidad Huilliche Chilote}

Una pregunta fundamental invade, falta confesarle, el investigador ansioso de entender los procesos complejos que afectan la percepción en la construcción de su propia identidad, entre las personas autodeclaradamente indígenas. En el caso que nos ocupa, los huilliche viviendo en la Isla Grande de Chiloé que han aportado, por lo menos en su tiempo, su preferencia a la acción sociocultural de la Federación ${ }^{11}$. Si, en definitiva, se registra la necesaria dinámica cultural que, en general, se traduce a través de cambios más o menos profundos y más o menos dolorosos para los grupos inmersos en estos contextos y mutaciones, no se descarta la legítima preocupación que el académico comparte con los sujetos que investiga. En suma, todos observamos la fragmentación en los ámbitos sociales, políticos y culturales que golpean de frente y en sus raíces a la comunidad mapuche huilliche en su conjunto. Con todo, este pueblo originario, al igual que todos los pueblos indígenas de este mundo, se ve también afligido por la complejidad, la diferenciación, la individualización, los cuestionamientos -y rechazos- a los marcos de referencias comunes a todos los grupos humanos: religión, organización, lealtades, ética. Dicho de otro modo, el hoy mucho más amplio mercado de los bienes simbólicos genera dudas y reevaluaciones inéditas entre los indígenas, acoplado ello con el contexto mutilador y discriminatorio del agresivo entorno cultural nacional y global ${ }^{12}$. Pertenecer a una comunidad (en el sentido amplio grupo de pertenencia así como en el más restringido lugar físico de vivencia), cuando se trata de evaluar los procesos de la construcción de la identidad, supone lazos afectivos suficientemente fuertes a la vez que no excluye, en definitiva, una 
participación creciente -aún laxa- en un mundo siempre más abierto. También en las realidades locales y regionales. Todo ello es entendible. Cada individuo, hoy por hoy, y probablemente a un ritmo siempre más acelerado, desarrolla sus actividades y aptitudes entre estos dos polos inseparables. Es igualmente el lugar complejo donde experimenta sus dudas y tomas de decisiones. En fin, es el tramo a lo largo del cual se pregunta cuáles son los rasgos que le diferencian de los otros a la par que les asemejan. Este espacio evoca la metáfora famosa de Pierre Bourdieu relativa a la arena en la que, se supone, todos los jugadores conocen las reglas del juego. Sin embargo, al retomarla para nuestra cuenta, no postulamos tal conocimiento por parte de los Huilliche de Chiloé puesto que no todos parecen poner frente a sí, como si fuese un desafío imperante, la meta de definir su grupo de pertenencia. Más bien muchos parecen actuar como si el juego ya fuese cancelado porque está ya jugado. Y adoptan las múltiples reacciones - generalmente desordenadas-de los vencidos...

En efecto, ¿tendrán todos los elementos para contestar las preguntas: a qué pertenecen? ¿a qué pueblo histórico pertenecen? ${ }^{13} \mathrm{Si}$, hipotéticamente, postulamos que es imperioso que los tengan, ¿qué contestan? En primer lugar, a la Isla, al inmenso y rudo campo chilote, a su inhóspito borde costero, al estado generalizado de abandono de la Isla y accesoriamente para otros, al pueblo mapuche huilliche. En segundo lugar, para los que afirman una clara y decidida identificación con el mismo, se asiste a un proceso inacabado y disparato de reapropiación de los fundamentos míticos y singulares de su pueblo. Es decir, reconstruyen un imaginario que les proporciona entusiasmo, orgullo y conciencia de afiliarse a la singularidad histórica y cultural del gran pueblo mapuche. De no figurar en esta opción que desemboca la mayoría de las veces en las presentes décadas sobre un activismo reivindicativo y demandas bien construidas pero todavía inarticuladas, los actores versan en lo que Rachik (2006) propone analizar como "identidades blandas" (opuestas a las "identidades duras"). Las identidades blandas serían, a partir de lo que se desprende de la propuesta del autor, inconsistentes, menos afirmadas y sustentándose sobre una mezcla de tradiciones provenientes de cunas diversas. El concepto, como se puede apreciar, tiene el mérito enfocar la observación detallista sobre las fisuras inherentes a los conjuntos culturales a los que muchos estudiosos solemos modelar una identidad inmaculada y esencial. Pese a las restricciones lógicas que aportan los especialistas, el esencialismo cultural no sirve a la emancipación de las minorías debido a que estas integran (e inducen) el sentimiento de culpa que les dirige la mayoría. En este sentido, es frecuente escuchar (con variaciones, evidentemente): "Nosotros los mapuche, no somos unidos", eco del refrán: "Ellos los mapuche no son cohesionados". Como si fuese extraño, en nuestros tiempos, que un pueblo no realizara el milagro de la unidad. Digamos francamente las cosas: si bien la noción de identidad y su corolario de continuidad sirven la causa de la inteligibilidad, desfavorece hasta entorpecer la acción de los frentes reivindicativos abanderados en las filas "blandas". En suma, tal visión estática se ve aprovechada por los que ocupan las cúpulas del poder para aplicar decisiones perentorias y unilaterales, sin consideración de la disparidad normal que singulariza a los grupos humanos, sobre todo si estos son minorías sin poder, despojadas y desarticuladas. O, para dejar en el limbo de la indeterminación, lo que se formula supuestamente mal. Es en esta atmósfera poca saludable que deben componer estrategias de sobrevivencia cultural o, en todos los casos, una armadura identitaria que será, en el mejor de los casos, satisfactoria. Sea esta blanda o dura. Además, sería menester vislumbrar con Rachik que "el uso de identidades colectivas como medio de movilización, como instrumento político, exige que el grupo en cuestión esté organizado (se esté organizando) de manera "informal" (tribu) o formal (asociación, partido político, etc.). (Rachik 2006:12. Énfasis mío). O sea, en el caso que nos ocupa, quizás no exista identidad colectiva huilliche chilota, quizás no estén organizándose y no se mantenga en la duración ninguna asociación formal...

Pero ¿no serán los lazos íntimos inexistentes o negados cuando el sentimiento de pertenencia o de participación es cuestionado o presentido como denigrante? Generando un alejamiento consciente y asumido de la filiación a un grupo indígena, para afiliarse a una construcción identitaria menos hostil. Es legítimo insistir sobre el hecho de que un legado étnico-cultural, caracterizado por los estigmas y la discriminación, no proporciona un entorno socioafectivo interpretativo favorable a la propia cultura y la afirmación identitaria. Tampoco, falta reconocerle, a la sociedad mayoritaria aunque supone, en definitiva, posibles mejoras para el futuro. En fin, la elección para -o, mejor dicho, el camino hacia- la 
identidad se cumple desde la discriminación, circunstancia que dejará sin duda perspectivas difícilmente benignas. Con las consecuencias imprevisibles que los vaivenes del propio ecosistema social y cultural pueden atizar. En todos los casos, estigmas, segregación, baja autoestima añadidos a la suma de los problemas diarios y rutinarios, constituyen una mala combinación para la construcción de la identidad. Probablemente asistimos a la carencia, o mejor dicho, a la reevaluación problemática, de "un nosotros instituyente que emerge como actualización de una ética y una política del reconocimiento desde el nosotros instituido, para quebrar la cáscara de hielo de su totalización" (Acosta 2005:24). Posibilidad que desemboca según los casos en la resiliencia cultural...

De otro lado, asumir y afirmar la identidad cultural es optar para la convivencia, i.e., el vivir en común, sobre el pilar de un destino colectivo cuyos efectos a nivel personal son innegables. Pensamos que, en la actualidad, la opción para el Huilliche chilote de reconocerse a sí mismo como tal, implica apostar sobre las promesas de su pueblo -como, definitivamente, lo hacen todos los grupos humanos-e inventar (imaginar) un horizonte que, por no alcanzarle, será su existencia misma que se vera minada y amenazada. Esta opción, en definitiva, exalta la espinosa cuestión "por el "yo" y el "nosotros" [y] por el vínculo social" y debe ser aprehendida desde el ángulo de las "minorías subordinadas" como "grupo vulnerable al poder económico y pol ítico respecto de la mayoría de la sociedad, que se organiza en torno a una identidad diferente de ésta y que hace visible esta diferencia pidiendo reconocimiento como tal" (Boitano 2010:1-2 ${ }^{14}$ ).

En este sentido, reconocemos que no existe grupo humano que pierda del todo su cultura o su identidad, ${ }^{15}$ fenómeno que traduce la increíble facultad que tienen los congregados culturales para generar, crear y producir cultura, pese a contextos radicales y opresivos que les sojuzgan con riesgos de perturbaciones mayores. Es menester contar igualmente con la invaluable capacidad de resistencia a la que, mal que bien, los pueblos originarios acostumbraron, a lo largo de su historia desde los primeros conflictos con los europeos, con los mestizos (o criollos) en seguida, con la cultura estado-nacional moderna y hasta las corrientes homogeneizadoras vinculadas a la llamada globalización. Si bien lo anterior no requiere de mucha demostración, nuestra frecuentación con personas autoproclamadas indígenas favorece una percepción matizada porque esta innegable resistencia se ve afectada seriamente por una serie de factores socioculturales globales propios a disturbar a todos los grupos culturales del planeta, sean o no "originarios". Evidentemente, existe una variedad de respuestas muy diferentes a esta coerción mayor y poderosa. No obstante, podría ser pueril disfrazar o rebajar las pérdidas irreversibles que los impactos originados en los efectos perturbadores y perversos de la oleada neoliberal, capaces de destrozar hasta las capas "tradicionales" más profundas, garantes habituales de perduración en un mundo acostumbrado desde muchos lustros a la diversidad. Evidentemente, debemos reconocer que nuestra apreciación no oculta una cierta nostalgia, y se la reprochará. Así las cosas, defendemos nuestra postura porque optamos firmemente por las declaraciones de nuestros informantes, deplorando todos sin excepción el limbo identitario en el que se encuentran. Creemos legítimo subrayar que sus discursos también son realidades y dignos de ser entendidos.

La situación cultural experimentada por los Huilliche de Chiloé remite potencialmente al terreno de la elección privada, a la par de la identidad cultural colectiva (sin que sea implícito negar las obvias consecuencias en este nivel). En efecto, podría depender del grado individual de integración y respuesta a los fenómenos y procesos de "aculturación-deculturación-neoenculturación" ${ }^{16}$. Con ello, queremos enfatizar la interacción y los conflictos que articulan la esfera colectiva con la esfera individual, en un movimiento de oscilación incesante. En suma, ¿qué es preferible? ¿la reproducción cultural sobre bases identitarias supuestamente inamovibles? ¿la guetoización?, o ¿la enculturación y asimilación? En realidad, es muy probable que los fenómenos analizados remitan a una combinación sutil, tanto a nivel individual como a nivel grupal, de cada una de las dinámicas mencionadas. Al fin y al cabo, es lícito arriesgar que los actores involucrados en estos procesos complejos toman una decisión personal, ciertamente influenciada por la socialización, siendo el rol del núcleo familiar imprescindible porque trasmite el "orgullo de ser mapuche" (sic!) y la internalización a partir del entorno social. Decisiones individuales cuya consecuencia tendrá el efecto "bola de nieve" en cuanto a las repercusiones a nivel colectivo, sin nunca descartar el hecho de que los grupos dominados, en su entorno socioterritorial, viven todas sus relaciones sobre un modo distributivo 
asimétrico así como las virtualidades sociales, económicas, políticas y culturales que les consiente el polo dominante. De ahí que no sorprenderán a nadie los grados de reacción que se eslabonan desde la mera sumisión a la subordinación, a lo largo de una cadena sorprendentemente larga.

No obstante, parecen pocos los huilliche chilotes que apostan sobre un enfoque proyectivo. En efecto, muchos son los índices que apuntan hacia una preocupación limitada en el presente (postura debida principalmente a la precariedad social y económica de la vida cotidiana). De ahí un gran desconocimiento (y despreocupación) en torno al pasado de lo que fue el pueblo huilliche y una selectividad en su aparato mítico, no histórico, con miras admirativas y cómplices hacia las turbulencias y alcances de los mapuche de la Novena Región, frecuentemente tomados y admirados como los modelos ejemplares de la lucha y de la identidad mapuche. A escala mínima, la gran mayoría se afana en recuperar su dignidad como pueblo originario, aun desconociendo los medios para llegar a tal objetivo, aun sin movilizarse y conformar un frente reivindicativo. Sencillamente lo desean a nivel humano. Recuperar para asumir la dignidad será, al fin y al cabo, un gran paso adelante para recrear un nosotros arraigado a un presente emulador y un pasado generador de proyecto en el futuro. En definitiva, "la construcción de una representación de sí mismo, en que pudiera integrarse lo que una comunidad ha sido con lo que proyecta ser" (Villoro 1998:57).

Frente a estas alternativas por nada simples de dilucidar, ni por parte de los interesados, ni del estudioso, no es capcioso cuestionar la lamentable situación de los derechos humanos, y en especial, indígenas en la que el Estado chileno deja los huilliche. No puede haber democracia creíble si los individuos ven sus derechos de autoadscripción limitados por, entre otras cosas, la discriminación insidiosa que se vive, generación tras generación, fomentando un modelo de sociedad en el que no existe la reciprocidad equitativa en la distribución y repartición de las oportunidades, por motivo, entre otras cosas, de pertenencia étnica. En fin, los hábitos culturales singulares de los huilliche en Chiloé (y en otras partes) son presentidos como poco compatibles con la sociedad global, motivo suficiente por el auto desprecio, la auto evaluación pesimista y la falta de consideración real para un nosotros problemático. Son, en breve, las enseñanzas que Seyla Benhabib ha entregado a partir de sus análisis de dilemas multiculturales ocurridos en los países centrales.

\section{Palabras Finales: un Sabor a Amargura...}

La Federación de Comunidades Huilliches de Chiloé constituye una experiencia distintiva al lograr articular a una ciudadanía emergente relacionada con las demandas de los pueblos originarios en un enfoque participativo (...) reforzando el valor de alternativas democráticas e innovadoras en la construcción de relaciones entre el Estado y los pueblos originarios, todo lo cual ha permitido avanzar en la recuperación de su propia identidad cultural (Cuyul 2006:4).

Con estas apreciaciones escritas por el propio fundador de la Federación, motivo de nuestras reflexiones, se puede apreciar con más discernimiento el derrumbe de las esperanzas que fueron inyectadas, entre otras metas, para la recuperación de la identidad deseada por la junta directiva de una asociación indígena ciertamente novedosa y original. Vale llamar la atención sobre el hecho de que el documento citado se ubica en medio camino entre la fundación de la misma y el momento en el que se redacta el presente ensayo. Es decir, en un momento clave en la aplicación de las políticas públicas en materia indígena por los gobiernos encabezados por la Concertación.

Muy probablemente se nos reprochará el fétido olor del pesimismo que nuestros análisis generan. Para nuestra defensa, confesaremos la preocupación y la tristeza que experimentamos con ocasión de los contactos repetidos que tenemos con nuestros informantes. ¿Cómo enfrentar la incertidumbre que genera su condición de "indígenas" - es deplorable que debamos recurrir a esta categoría imprecisa- conscientes de su pertenencia a una nación humillada?, ¿cómo resolver las inquietudes e imprecisiones que caracterizan las numerosas corrientes contradictorias frente a un aparato estatal acostumbradamente poco proclive a la negociación?

Con argumento del relativo pesimismo de nuestras apreciaciones, constatamos que el pueblo huilliche -tal vez más todavía en el caso de los huilliche chilotes- no llega a definirse ni describirse a sí mismo frente a los que, mezquinamente, aprovechan su desconcierto para extender el dominio de su hegemonía. Preguntamos ¿dónde está la concreción, o sea, la expresión concreta del pueblo 
huilliche? Afirmándonos en Villoro, descartamos la acusación de que nuestra apreciación reflejaría una serie de abstracciones pensadas por un investigador exterior y ajeno a este pueblo, como lo son sus colegas estudiosos acostumbrados a singularizar los grupos que analizan a partir de criterios, y a priori, etnocéntricos (creando una alteridad abstracta y poco conveniente), sino que deseamos cuestionar la aparente inexistencia de proyecto común al pueblo huilliche. En definitiva ¿qué quiere ser este pueblo? Si es que quiera ser algo. "El 'sí mismo' no es sólo que se es, sino lo que ha de llegar a ser (...), pues un pueblo debe llegar a ser lo que ha eligido" (Villoro 1998:66. Cursivas mías).

De no poder responder a tiempo a esta espinosa duda, es la existencia misma del grupo mapuche que se podría ver seriamente amenazada.
Agradecimientos: Este trabajo fue elaborado en el marco del proyecto del CONICYT 80100004 "Discursos y Prácticas Territoriales: Comunidades Huilliche de las Provincias de Osorno y Chiloé", base del Concurso Atracción de Científicos/as y/o Expertos/as del Extranjero a Chile, Modalidad Estadías Cortas (MEC). El autor desea expresar su reconocimiento al CONICYT así como a la institución albergante, Universidad de Los Lagos, Centro de Estudios Regionales, las facilidades que se le proporcionaron durante estos meses. De igual forma, el autor agradece a Ángela Boitano los intercambios de ideas y dudas que alimentaron el presente trabajo. Se agradece también a los evaluadores por el tiempo invertido y por sus valiosas sugerencias.

\section{Referencias Citadas}

Acosta, Y. 2005. Nuestra América: vigencia y validez. http:// www.revistadialectica.org/37/archivos/37_nuestra_america. pdf. (01 octubre 2011).

Boitano, A. 2010. Minorías subordinadas: noción de "sujeto" y prácticas de resistencia. Ponencia presentada en el II Congreso Internacional Ciencias, Tecnologías y Culturas. Diálogo entre las disciplinas del conocimiento. Hacia el futuro de América Latina y el Caribe, Santiago de Chile.

- - - 2011. Demanda mapuche: tensión entre identidad y diferencia, ciudadanía y comunidad, particularismo y universalismo. Polis Revista de la Universidad Bolivariana10:307-321.

Boissier, S. 2010. Descodificando el desarrollo del siglo XXI: subjetividad, complejidad, sinapsis, sinergia, recursividad, liderazgo y anclaje territorial. Semestre Económico13 (27):11-37. Medellín.

Bourdieu, P. 1980a. Le Sens Pratique. Minuit, Paris.

- - - 1980b. L'identité et la représentation. Eléments pour une réflexion critique sur l'idée de región. En Actes de la Recherche en Sciences Sociales 35, pp. 63-72, EHESS, Paris.

- - - 1984. Sociología y Cultura. Grijalbo, México.

- - - 1987. Choses Dites. Minuit, Paris.

- - - 1994. Raisons Pratiques. Sur la Théorie de l'Action. Seuil, Paris.

Cuyul, S. 2006. Federación de Comunidades Huilliches de la Isla de Chiloé. Manuscrito en posesión del autor.

De la Calle Ysern F.J.1986. Los Huilliches de Chiloé. La Defensa de la Tierra de unos Indios Chilenos. Memoria de licenciatura, Universidad Complutense, Madrid.

Programa de Derechos Indígenas 2003a. Los derechos de los mapuches huilliche de Valdivia y Osorno. En Los Derechos de los Pueblos Indígenas en Chile, editado por el Instituto de Estudios Indígenas, pp. 299-323, Universidad de La Frontera, LOM, Santiago.
Programa de Derechos Indígenas 2003b. Los derechos del pueblo huilliche de la Isla Grande de Chiloé. En Los Derechos de los Pueblos Indígenas en Chile, editado por, Instituto de Estudios Indígenas, pp. 325-344. Universidad de La Frontera, LOM, Santiago.

Díez Guttiérez, E.J. 2004. Interculturalidad, convivencia y conflicto. Tabanque 18:49-76.

Fornet-Betancourt, R. s/f. Lo intercultural: el problema de su definición.http://www.aulaintercultural.org/IMG/pdf/betancour. pdf. (22 septiembre 2011).

Martín Criado, E. 2009. Habitus. En Diccionario Crítico de Ciencias Sociales. Terminología Científico-Social. Dirigido por R. Reyes, Plaza y Valdés, Madrid y México. http://www.ucm. es/info/eurotheo/diccionario/habitus.htm

Martínez Bonati, F. 2005. Nación y cultura. Estudios Públicos 99:5-22.

Rachik, H. 2006. Identidad dura e identidad blanda. Revista CIDOB d'Afers Internacionals 73-74:9-20.

Ramírez, E., F. Modrego, J.C. Macé y R. Yáñez 2009a. Dinámicas territoriales en Chiloé Central: la fuerza de las coaliciones extra territoriales. En Dinámicas Territoriales Rurales. Documento de Trabajo 54. Rimisp, Santiago.

- - - 2009b. Caracterización de los actores de Chiloé Central. En Dinámicas Territoriales Rurales. Documento de Trabajo 55. Rimisp, Santiago.

Sauriol, L. 2005. Interculturalidad y construcciones identitarias en la narrativa de Mayra Santos Febres: una propuesta de diálogo dialógico. Tinkuy, Sección de Estudios Hispánicos 1:93-101.

Villoro, L. 1998. Estado Plural, Pluralidad de Culturas. UNAM/ Paidós, México.

Walsh, C., W. Mignolo y A. García Linera 2006. Interculturalidad, Descolonización del Estado y del Conocimiento. Ediciones del Signo, Buenos Aires. 


\section{Notas}

1 Pese a las dificultades epistemológicas que este concepto tan en boga en nuestra época recela, pensamos permitido utilizarle para referirse a este bagaje en perpetua remodelación sobre el cual y a partir del cual se fundamentan los entes individuales o colectivos para diferenciarse de los otros percibidos como diferentes. En suma, un conjunto nunca definitivo de referentes elementales que conforman la mismidad.

2 Es decir, el Consejo General de Caciques, reconocido de manera nominalmente pero no extensivamente en el artículo 61 de la Ley Indígena 19.253 de 1993, como la estructura jurídico-política del pueblo huilliche de Chiloé. "Lamentablemente, estas disposiciones [las del artículo 61] no han sido interpretadas por las autoridades chilenas de una manera extensiva y solo tienen un carácter nominal. Además el estado no ha generado las condiciones para "relacionarse adecuadamente con los caciques", tampoco existen actos de significación política (...)". En "Los derechos del pueblo huilliche..." (Programa de Derechos Indígenas 2003b:331-332).

3 Consultar Ramírez et al. (2009a) y (2009b).

4 Varios informantes señalan un trato diferente en la atención que reciben, por ejemplo, en las postas médicas.

5 Basta con mandar a nuestros lectores a Bourdieu (1980:102 y 129-130) por ejemplo, donde el propio teórico enfatiza el "arbitrario cultural" quedetermina las estructuras y contra el habitus que "tiende aasegurar su propia constancia [tal como] un mecanismo de defensa contra el cambio".

6 Con motivo de la restitución de tierras, el documento citado precisa textualmente: "la devolución por parte del Estado de las tierras ancestralmente indígenas, lográndose este objetivo el año 2005 , fecha en la cual se devuelve a las comunidades el $80 \%$ de las tierras reclamadas por ellas, quedando aún un remanente en vías de traspaso. En ese entonces fueron beneficiadas un total de 9 comunidades, lo que significó un logro notable y se constituyó en un hito para la Federación, ya que ha mejorado ostensiblemente la calidad de vida de más 200 familias indígenas".

7 Es preciso recordar que las incongruencias e ineficiencias en las políticas públicas en materia indígena (en especial la nula coordinación entre CONADI y los servicios públicos) pueden haber justificado abusos en las pretensiones territoriales por parte de las empresas privadas, ocasionando graves lesiones en el derecho territorial huilliche. Es una manera de apuntar el hecho de que CONADI no obtuvo impacto social ninguno en la isla de Chiloé. Y probablemente contribuyó a una nueva distribución tanto cultural como política en el complejo ajedrez huilliche chilote.

8 Es indispensable considerar, a nivel general, que "en cuanto a las asociaciones indígenas, si bien se han conformado varias de ellas en la provincia, no existen experiencias de gran relevancia por lo escaso de los aportes a los que ellas postulan y debido a la falta de legislación complementaria que beneficie las iniciativas económicas de los indígenas". ("Los derechos del pueblo huilliche" Programa de Derechos Indígenas 2003b:332). Tal hecho constituye indudablemente un limitante supremo para la labor de dichas asociaciones.
9 La situación general, a nivel cultural, entre los mapuche huilliche de Chiloé demuestra una falta de articulación inquietante, tal vez debida, entre muchos factores, a la carencia de intelectuales originarios capaces de analizar y proponer alternativas genuinas y orgánicas a la par de divulgarlas en un público tanto huilliche como winka. Ilustraremos esta apreciación remarcando que uno de los pocos sitios de Internet relacionado directamente a los huilliche de Chiloé recalca en torno al "Territorio Mapuche Huilliche de Chiloé" -es el título de la publicación- lo que parece ser solamente una reseña histórica hasta el Tratado de Tantauco, a principios del siglo XIX (1826), dejando en la sombra la situación actual. Ver http://kutralwe-chile.webnode.es/products/ territorio-mapuche-huilliche-de-chiloe/.

10 Posiblemente estas categorías sean "occidentales". Lo que refleja entonces la apropiación con la que los huilliche llegan a autoapreciarse. Ahora bien, la envidia..., ¿categoría occidental? El que escribe ha trabajado varios años en comunidades nahuas de México donde la "envidia" se denomina nexicolis, y es la causa de una serie de síndromes que enfrentan los chamanes para dilucidar y desentramar profundos disturbios personales y colectivos.

11 Nuestros encuentros con los interesados son en definitiva limitados. Ningún etnólogo puede vanagloriarse haberse encontrado y entrevistado a todo un grupo. Nuestras informaciones se basan en gran parte sobre tres fuentes: una decena de entrevistas abiertas y semiabiertas a actores seleccionados por la diversidad de roles que asumen en sus lugares y comunidades, los intercambios libres con sus familiares, y en los múltiples diálogos que pudimos llevar a cabo con el responsable de la Federación, Sergio Cuyul. Igualmente en varios intercambios electrónicos con el mismo, o en notas directas que hizo el favor proporcionarnos como comentarios a manuscritos e informes nuestros que pensamos divulgar entre los comuneros. Muchos de los datos recopilados relativos a los trastornos en la identidad van, no obstante, en el sentido de entrevistas a profundidad que realizamos en el 2009, en la zona sureste de la Isla Grande, Compu y Chadmo. Vale precisar que, pese a las diferencias innegables que existen entre los huilliche de San Juan de la Costa, Puyehue o San Pablo (territorio continental) y los de Chiloé, aparece la misma intensa preocupación en torno a lo que llaman la "pérdida de la cultura" o el "desconocimiento de la cosmovisión mapuche" entre los propios indígenas. Empero, no pensamos permitido extender las conclusiones que retiramos a partir de la experiencia vivida entre los huilliche afiliados a la Federación hacia sus hermanos viviendo otros contextos territoriales e históricos. Después de todo, las semejanzas podrían engañarnos y dar impresiones generales impropias a nuestras observaciones.

12 Coincidimos en gran parte con la postura de Boissier cuando sostiene que "los mapuches (...) jamás llegarán a ser desarrollados en Chile (...) a menos que [la sociedad chilena] cambie sus valores, elimine el racismo y el clasismo" (Boissier 2010:19).

13 A esta pregunta eventual, la opinión de un alto dirigente mapuche en Chiloé, si parece drástica, expresa indudablemente la 
percepción de un responsable particularmente bien informado en torno a lo que conmueve, o no, a su gente. Escribe: "La memoria histórica es algo que (...) acá en Chiloé carecemos de ella, nuestra memoria histórica es corta, no existe conciencia de la manera que se perdió la tierra, por ejemplo, ni lo que fuimos como pueblo en el pasado mediato. Y esto ha ocasionado confusión, soberbia y fundamentalmente divisiones (comunicación personal 2011).
14 Una versión mucho más acabada de este producto se encuentra en Boitano 2011.

15 En términos de Boitano "nunca se pierde identidad (...) sino otra identidad que se reconfigura"(comunicación personal 2011).

16 Se nos permitirá esta fórmula compleja que sólo desea enfatizar las sinergias que actúan en los procesos tanto internos como externos. 

ANDROS IMPRESORES

www.androsimpresores.cl 
